\title{
The management of a pregnant patient with malaria in West Texas
}

\author{
Hanna Kodeih DO, James Maher MD, David Moore MD, Natalia Schlabritz-Lutsevich MD
}

\begin{abstract}
Travel associated infectious disease, such as malaria, should be considered in returning travelers from an endemic area presenting with fever. Malaria in pregnancy has a high maternal and fetal morbidity and mortality burden. Early diagnosis is essential to improve maternal and fetal outcomes by providing maternal supportive measures and anti-malarial medication.

We present a patient with severe acute febrile illness with mental status changes at 32 weeks gestation. She became acutely symptomatic including high grade fever while visiting West Texas from Nigeria. Despite initial diagnostic uncertainty, a multidisciplinary team successfully diagnosed and treated her severe malaria. She delivered at term with no long lasting maternal or fetal sequelae from her malarial infection. In an age of globalization, travel associated infectious diseases should be considered in the differential of acute febrile illness in pregnant women.
\end{abstract}

Keywords: obstetrics, malaria, critical care in pregnancy

\section{INTRODUCTION}

International air travel has promoted the spread of tropical diseases. ${ }^{1}$ The spread of Zika virus to the Americas has acutely focused attention on both the importing of mosquito borne illness and screening for potential Zika virus exposure in patients who recently traveled to endemic areas. ${ }^{2}$ Despite the recent concern about Zika virus, the CDC Surveillance for Travel-Related Disease report lists falciparum malarial infection as the most contracted travel associated infectious disease due to high prevalence of this disease in tropical areas and infrequent use of prophylaxis by travelers. ${ }^{1,3}$ Providers should consider common travel associated infectious diseases in their differential diagnosis of febrile patients with recent travel to endemic areas.

Adverse outcomes from severe acute malaria in pregnancy include maternal anemia, intrauterine

Corresponding author: Hanna Kodeih

Contact Information: Hanna.kodeih@ttuhsc.edu DOI: 10.12746/swrccc.v7i28.545 growth restriction, low birth weight, preterm birth, miscarriage, perinatal death, and maternal death. Severe malaria is characterized as acute malaria with signs of organ dysfunction, or parasitemia $>5 \% .4,5,6$ Manifestations of organ dysfunction include impaired consciousness, convulsions, acidosis, hypotension, jaundice, severe anemia, pulmonary edema, and shock. ${ }^{7}$ Early diagnosis and aggressive treatment of malaria infections in pregnancy has been shown to greatly improve outcomes for mother and fetus. ${ }^{8}$

\section{Case Presentation}

Our patient was a 35-year-old Nigerian female G2P1001 at 32 weeks and 5 days gestation by last menstrual period consistent with early ultrasound. While on vacation to visit her sister in West Texas, she became ill and presented to labor and delivery with a 4-day history of fever to $103^{\circ} \mathrm{F}$, painful contractions, myalgia, disorientation, and arthralgias. She was seen three days earlier at a different facility with similar complaints and was discharged with the diagnosis of false labor. The fever history was apparently not addressed. On presentation to our facility, she did 
Table 1. Admission vital signs

\begin{tabular}{|l|l|}
\hline \multicolumn{2}{|l|}{ Vital signs } \\
\hline Blood pressure & $88 / 38 \mathrm{mmHg}$ \\
\hline Temperature & $38.6^{\circ} \mathrm{C}$ \\
\hline Heart rate & $140 \mathrm{bpm}$ \\
\hline $\mathrm{O}_{2}$ saturation & $99 \%$ on $2 \mathrm{~L} \mathrm{O}_{2}$ per minute \\
\hline FHR Tracing & $\begin{array}{l}\text { Cat 2: Baseline 200, moderate } \\
\text { variability, recurrent late decelerations }\end{array}$ \\
\hline Tocometer & Ctx q 2-3 minutes \\
\hline
\end{tabular}

not report any significant past medical history, but her communication was limited by her disorientation and a language barrier. Patient denied any sick contact and unusual exposures to sick animals or arthropods and had arrived in Texas from Nigeria 4 days prior. She denied taking any medications. Past surgical history was significant for one prior low transverse cesarean delivery for arrest of dilation in Nigeria. She was clinically ill with profound diaphoresis, painful contractions, persistent fever, and hypotension on presentation (Table 1). Cardiac auscultation revealed maternal tachycardia with systolic ejection murmur grade IV/VI.
Her cervix was closed with no effacement on digital examination. Sublingual jaundice and scleral icterus were noticed. Contractions were present every two minutes, and a category II fetal heart rate tracing was observed with moderate variability but recurrent late decelerations and fetal tachycardia (Figure 1).

Our differential diagnosis included malarial disease and other acute syndromes, such as influenza, sickle cell crisis, hepatitis, varicella, pneumonia, Zika, complicated urinary tract infection, pyelonephritis, meningitis, sickle cell crisis, and other vector borne diseases. Her initial laboratory results are reported in Table 2 and were significant for increased lactic acid $(2.8 \mathrm{mg} / \mathrm{dl})$, elevated bilirubin (3.2 $\mathrm{mg} / \mathrm{dL})$, and ketones and urobilinogen $>12$ on urinalysis. Maternal supportive measures initiated at presentation included fluid resuscitation, indomethacin tocolysis, intravenous acetaminophen for fever, and betamethasone for induction of fetal lung maturity. The patient's condition improved following our initial treatment. The fever and contractions resolved and the fetal heart rate tracing improved. After several hours, an additional family member arrived and was able to provide a more complete past medical history. Her sister informed us that the patient had a history sickle cell trait and a remote history of malaria infection which was

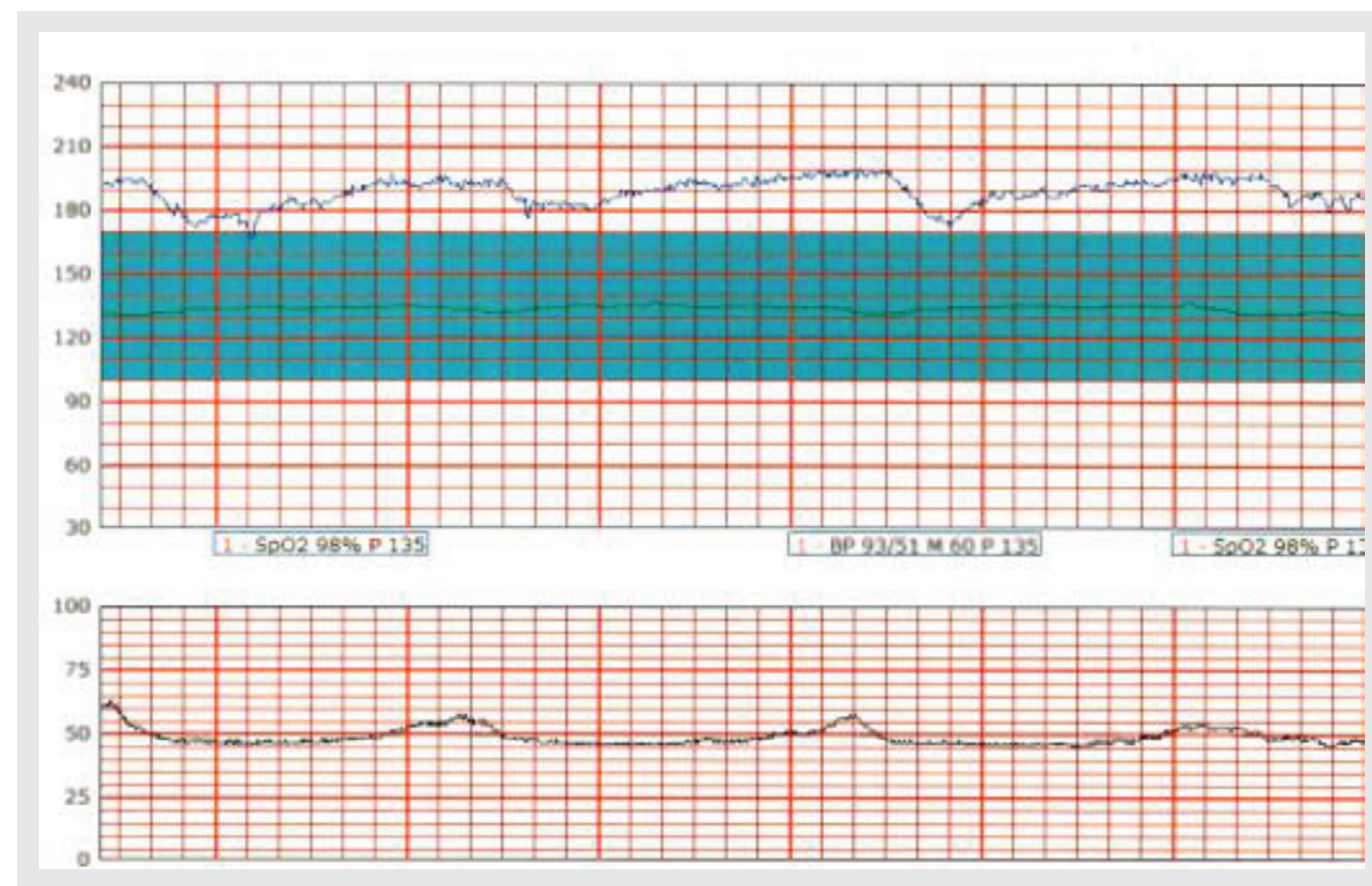

Figure 1. Fetal strip. Baseline 200 with recurrent late variable decelerations; category 2 strip. 
Table 2. Admission laboratory tests

\begin{tabular}{|c|c|c|c|c|c|}
\hline WBC & $6.4 \mathrm{~K} / \mu \mathrm{L}$ & Glucose & $74 \mathrm{mg} / \mathrm{dL}$ & Albumin & $2.9 \mathrm{~g} / \mathrm{dL}$ \\
\hline $\begin{array}{l}\mathrm{Hb} \\
\mathrm{Hct}\end{array}$ & $\begin{array}{l}11.5 \mathrm{~g} / \mathrm{dL} \\
32.1 \%\end{array}$ & $\begin{array}{l}\text { BUN } \\
\mathrm{Cr}\end{array}$ & $\begin{array}{l}8 \mathrm{mg} / \mathrm{dL} \\
0.6 \mathrm{mg} / \mathrm{dL}\end{array}$ & Alk P & $169 \mathrm{IU} / \mathrm{L}$ \\
\hline $\mathrm{MCV}$ & $73.1 \mathrm{fL}$ & $\mathrm{Na}$ & $136 \mathrm{mEq} / \mathrm{L}$ & Bilirubin & $3.2 \mathrm{mg} / \mathrm{dL}$ \\
\hline PLT & $105 \mathrm{~K} / \mu \mathrm{L}$ & $\mathrm{K}$ & $3.0 \mathrm{mEq} / \mathrm{L}$ & $\begin{array}{l}\text { Urine } \\
\text { Culture }\end{array}$ & Negative \\
\hline $\begin{array}{l}\text { AST } \\
\text { ALT }\end{array}$ & $\begin{array}{l}25 \mathrm{IU} / \mathrm{L} \\
20 \mathrm{IU} / \mathrm{L}\end{array}$ & $\mathrm{Cl}$ & $106 \mathrm{mmol} / \mathrm{L}$ & Blood Culture & No growth \\
\hline Lactic Acid & $2.8 \mathrm{mg} / \mathrm{dl}$ & $\mathrm{CO}_{2}$ & $18 \mathrm{mmol} / \mathrm{L}$ & Urine Dip & $\begin{array}{l}+ \text { Ketones (20) } \\
\text { Urobilinogen }>12 \\
\text { Ictotest }+\end{array}$ \\
\hline
\end{tabular}

successfully treated with trimethoprim-sulfadoxine prior to the current pregnancy.

The patient's initial laboratory evaluation suggested hemolysis and anemia. A routine peripheral smear showed banana shaped malarial parasites in the RBC The specific organism and parasite load were unknown at that time. The first line treatment suggested by our literature review, artesunate, was not available in our pharmacy. Consultation between the on-call expert at the CDC and our pharmacy led to successful empiric quinine-based therapy. The patient was moved to the intensive care unit (ICU) for telemetry monitoring prior to beginning treatment with IV quinidine $(10 \mathrm{mg} / \mathrm{kg}$ loading dose followed by $0.2 \mathrm{mg} / \mathrm{kg} / \mathrm{minute}$ continuous infusion for 48 hours) and oral clindamycin $(20 \mathrm{mg} / \mathrm{kg} /$ day divided into 8 hours for 7 days). Successful management in the ICU required coordination between the intensivist physicians \& ICU staff, labor and delivery nurses (for continued fetal monitoring in the ICU), infectious disease specialists, pharmacy, obstetrician, pathology, and maternal fetal medicine. Final pathology report of the malaria Giemsa stain was returned 24 hours after admission that revealed presence of $P$. falciparum. She was treated in the ICU with IV quinidine for 72 hours and subsequently completed a 7-day course of oral clindamycin.

After successful inpatient stabilization, she continued with prenatal care at our institution. Antenatal testing and ultrasonography were offered due to the risk of fetal congenital infection with maternal falciparum malarial infection. The patient refused outpatient weekly antenatal testing. Ultrasound at 36 weeks showed a pericardial effusion $>4 \mathrm{~mm}$ and estimated fetal weight in the 44th percentile (Figure 2). The amniotic fluid index was normal, and the placenta was grade II. The fetal heart was structurally normal with no sign of hydrops, but evaluation of the middle cerebral artery showed increased peak systolic velocity

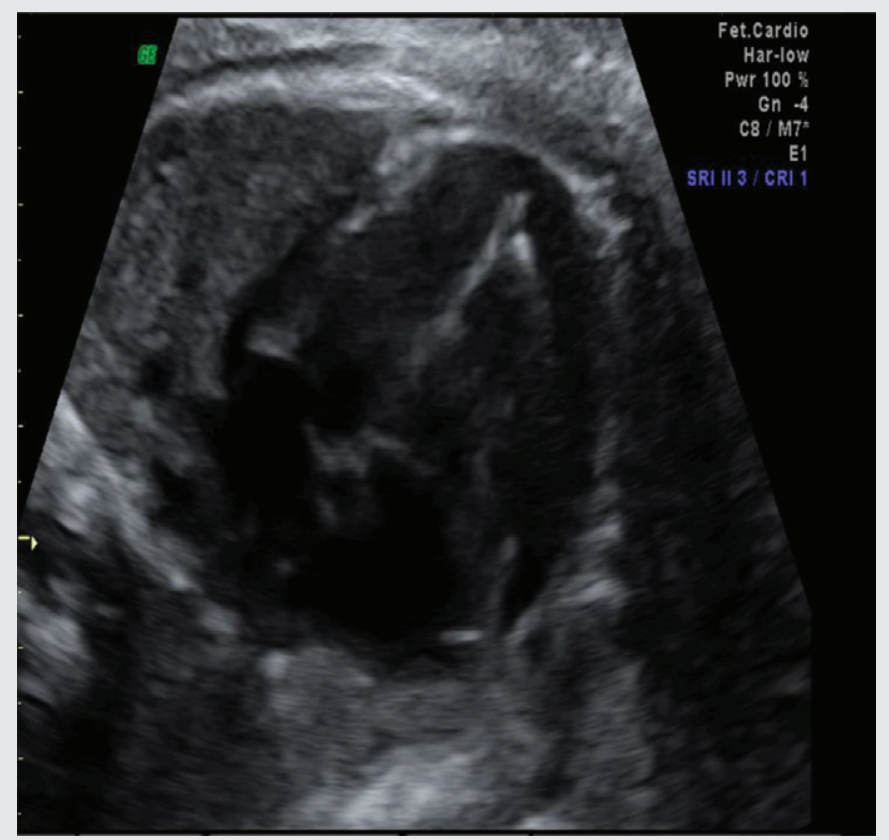

Figure 2. Pericardial effusion seen in fetal echocardiogram. 


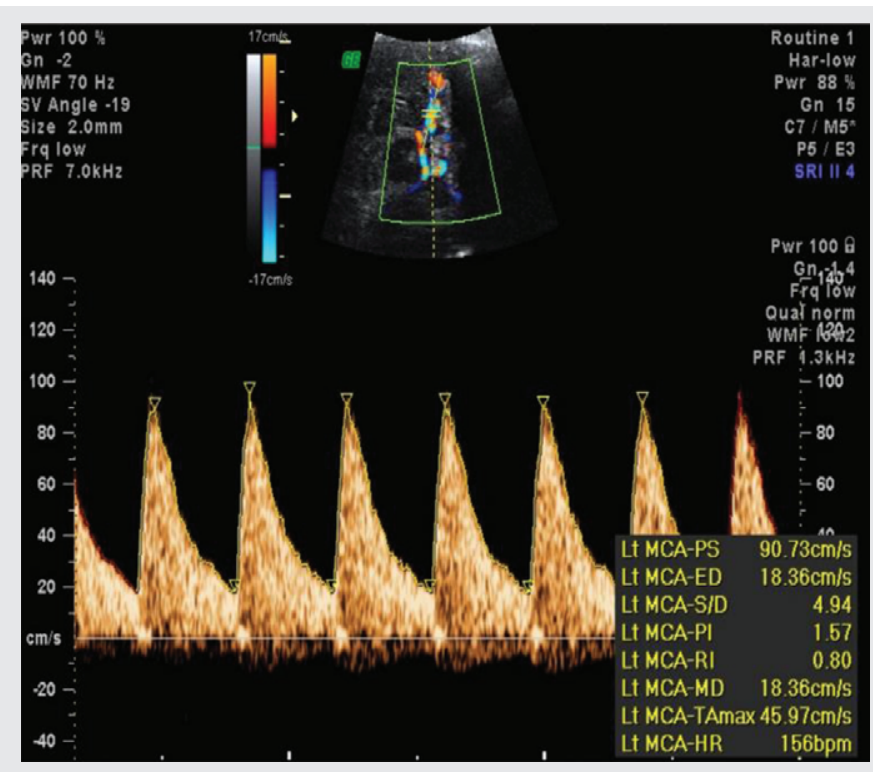

Figure 3. Elevated peak systolic velocity seen in middle cerebral artery Doppler.

(PSV) value of $90 \mathrm{~cm} / \mathrm{sec}$ which was calculated at 1.68 Multiples of the Median suggestive of fetal anemia (Figure 3). There was right atrial enlargement but no valvular regurgitation. The biophysical profile was reassuring, and umbilical flow velocity waveforms were normal. Delivery was recommended, and a viable female infant was delivered with Apgar scores of 9/9 and weight $2950 \mathrm{~g}$. Fetal malaria smear was negative. Fetal laboratory findings showed mild anemia with hemoglobin at $12.2 \mathrm{~g} / \mathrm{dl}$, but the infant did well and was discharged home with mother two days after delivery. Placental pathology was unremarkable with no evidence of active parasitic infection.

\section{Discussion}

The worldwide prevalence of Malaria in pregnancy is about 50 million cases per year, half of which are in Africa. Annually 10,000 women and 200,000 infants die as a direct result of acute malaria. ${ }^{9,10}$ Malaria is more likely to manifest as a severe infection in pregnancy due to several factors, including the immune modulation of pregnancy which can increase peripheral circulating parasite load and sequestration of $P$. falciparum within the placenta. ${ }^{4,6,10,11,12}$ Clinical presentation of acute malaria infection includes chills, cyclic fevers, diaphoresis, headache, myalgia, fatigue, nausea, abdominal pain, vomiting, diarrhea, jaundice, contractions, and cough. ${ }^{13,14}$ While the gold standard for malaria diagnosis is polymerase chain reaction, Giemsa stain of a thin peripheral blood smear has historically been used and may be more readily available. ${ }^{14,15}$ According to the World Health Organization, the recommended treatment for acute severe infection with $P$. falciparum is parenteral artesunate, which inhibits parasite metabolism and enhances clearance of infected erythrocytes. ${ }^{14,17,18,19,20}$ In the US, CDC guidelines recommend treatment of severe malaria with quinidine and one of the following: doxycycline, tetracycline, or clindamycin. ${ }^{17}$ The mechanism of action for quinidine as an antimalarial is not fully understood but may be related to the parasite's metabolism of hemoglobin..$^{20,21}$ Treatment with quinidine requires cardiac monitoring with telemetry in the intensive care unit, as elevated serum quinidine levels cause QT prolongation and ventricular tachycardia. ${ }^{14,18,20}$ Blood glucose should also be monitored, since this drug can cause maternal and fetal hypoglycemia. The CDC has malaria experts on call to assist with treatment options, and, if quinidine fails to treat the infection, artesunate may be available with an investigational new drug protocol. ${ }^{17,22}$

$P$. falciparum has been shown to cause fetal congenital infection. , 11,12 There is no clear consensus for optimal antepartum management following maternal stabilization after an acute malarial infection. Several case reports have suggested following maternal hemoglobin and fetal growth. ${ }^{11}$

According to the CDC, the endemic risk of malaria in Texas approaches zero, and the likelihood of seeing and treating malaria in the desert of West Texas is rare with only 100 reported cases in 2015 , all of which were imported. ${ }^{23}$ However, international travelers can present with tropical diseases, such as yellow fever, malaria, West Nile virus, and Zika. For some of these diseases the pre-symptomatic incubation period is longer than the travel time. These diseases should be included in the differential diagnosis of an acute febrile illness when a patient's travel history suggests exposure to an endemic area. With a patient who is critically 
ill and meets criteria for sepsis, clinical urgency and an inclusive differential diagnosis can greatly impact patient outcomes. ${ }^{24}$

Obtaining the correct diagnosis required a thorough history, detailed physical examination, and consideration of non-native causes of febrile illnesses. Because of the low incidence of malaria in Texas found in individuals recently traveling from endemic areas outside the U.S., practitioners with experience in management of this disease are uncommon in rural areas. Fortunately, experts from the CDC were readily available and worked synchronously with a multidisciplinary patient care team, including representatives from obstetrics, pathology, infectious disease, pharmacy, and intensive care, to optimally manage the patient. At all times, the ICU team and obstetrics team had open communication to coordinate the care of both the mother and fetus. Collaboration between the CDC experts and the hospital pharmacy is essential as not all pharmacies carry quinine on formulary.

The CDC has guidelines to differentiate severe and non-severe malarial infection. This patient met multiple criteria for severe malaria infection: maternal hypotension, infection with $P$. falciparum, initial presentation with abnormal behavior, and evidence of jaundice on initial physical examination. $P$. falciparum remains the main cause of malaria leading to maternal and fetal mortality. ${ }^{6}$ Fatality is predominately caused by severe anemia, metabolic acidosis, and/or cerebral malaria. There is often a continuum from asymptomatic malaria to severe malaria. However, if severe malaria is suspected, immediate treatment should be initiated to reduce the risk of mortality.

Maternal stabilization and support was our primary initial goal and treatment of the mother improved the fetal condition. The patient received aggressive fluid support and antipyretic and anti-malarial therapy. With these measures, the fetal heart rate tracing improved, with a transition of the fetal strip to Category 1. As outlined in the critical care practice bulletin, stabilizing the maternal condition takes precedence and expedited delivery should not be considered initially. ${ }^{23}$ Delivering the patient would have not improved maternal outcome and may have resulted in worse outcomes for both the patient and her infant.
Article citation: Kodeih H, James Maher J, David Moore D, Schlabritz-Lutsevich N. The management of a pregnant patient with malaria in West Texas. The Southwest Respiratory and Critical Care Chronicles 2019;7(28):47-52

From: The Department of Obstetrics and Gynecology, Texas Tech Health Science Center in the Permian Basin, Odessa, Texas

Submitted: $10 / 15 / 2018$

Accepted: 4/4/2019

Reviewers: David Sotello MD, Edward Yeomans MD Conflicts of interest: none

This work is licensed under a Creative Commons Attribution-ShareAlike 4.0 International License.

\section{REFERENCES}

1. Angelo KM, Libman M, Caumes E, et al. Malaria after international travel: a GeoSentinel analysis, 2003-2016. Malar J 2017;16(1):293.

2. Imperato PJ. The convergence of a virus, mosquitoes, and human travel in globalizing the Zika epidemic, 2016. J Community Health; 41(3):674-9.

3. Harvey K, Esposito DH, Han P, et al. Surveillance for travelrelated disease-GeoSentinel Surveillance System, United States, 1997-2011. MMWR Surveill Summ 2013;62:1-23.

4. Whitty CJ, Edmonds S, Mutabingwa TK. Malaria in pregnancy. BJOG 2005;112(9):1189-95.

5. Espinoza E, Hidalgo L, Chedraui P. The effect of malarial infection on maternal-fetal outcome in Ecuador. J Matern Fetal Neonatal Med 2005;18(2):101-5.

6. Granja AC, Machungo F, Gomes A, et al. Malaria-related maternal mortality in urban Mozambique. Ann Trop Med Parasitol 1998;92(3):257-63.

7. Severe malaria. Trop Med Int Health 2014;19 Suppl 1:7-131.

8. Burger RJ, van Eijk AM, Bussink M, et al. Artemisinin-based combination therapy versus quinine or other combinations for treatment of uncomplicated Plasmodium falciparum malaria in the second and third trimester of pregnancy: a systematic review and meta-analysis. Open Forum Infect Dis. 2016;12;3(1): ofv170.

9. Newman RD, Hailemariam A, Jimma D, et al. Burden of malaria during pregnancy in areas of stable and unstable transmission in Ethiopia during a nonepidemic year. J Infect Dis 2003;187(11):1765-72.

10. Uneke CJ. Congenital Plasmodium falciparum malaria in sub-Saharan Africa: a rarity or frequent occurrence? Parasitol Res 2007;101(4):835-42. 
11. Griffin JB, Lokomba V, Landis SH, et al. Plasmodium falciparum parasitaemia in the first half of pregnancy, uterine and umbilical artery blood flow, and foetal growth: a longitudinal Doppler ultrasound study. Malar J 2012;11:319.

12. Kattenberg JH, Ochodo EA, Boer KR, et al. Systematic review and meta-analysis: rapid diagnostic tests versus placental histology, microscopy and PCR for malaria in pregnant women. Malar J 2011;10:321.

13. Malaria. World Health Organization. http://www.who.int/ malaria/en/. Accessed 11/30/2018.

14. White NJ, Pukrittayakamee S, Hien TT, et al. Malaria. Lancet 2014;383(9918):723-35.

15. Frean J. Improving quantitation of malaria parasite burden with digital image analysis. Trans R Soc Trop Med Hyg 2008; 102(11):1062-3.

16. Peixoto HM, Marchesini PB, de Oliveria MR. Efficacy and safety of artesunate-mefloquine therapy for treating uncomplicated Plasmodium falciparum malaria: systematic review and meta-analysis. Trans R Soc Trop Med Hyg 2016.
17. Guidelines for Treatment of Malaria in the United States. Centers for Disease Control. https://www.cdc.gov/malaria/ resources/pdf/treatmenttable.pdf. Accessed 11/30/2018.

18. Mehta SR, Das S. Management of malaria: recent trends. J Commun Dis 2006;38(2):130-8.

19. Olliaro P. Mode of action and mechanisms of resistance for antimalarial drugs. Pharmacol Ther 2001;89(2):207-19.

20. Rosenthal PJ. Antiprotozoal drugs. In: Katzung BG, Masters SB, Trevor AJ, editors. Basic \& Clinical Pharmacology, 14e New York, NY: McGraw-Hill; 2017.

21. Olliaro P. Mode of action and mechanisms of resistance for antimalarial drugs. Pharmacol Ther 2001;89(2):207-19.

22. Artesunate is available to treat severe malaria in the United States.Centers forDisease Control.https://www.cdc.gov/malaria/ diagnosis_treatment/artesunate.html. Accessed 11/30/2018.

23. Mace KE, Arguin PM, Tan KR. Malaria Surveillance-United States, 2015. MMWR Surveill Summ 2018;67(No. SS-7): 1-28. DOI: http://dx.doi.org/10.15585/mmwr.ss6707al

24. Critical care in pregnancy. Obstet Gynecol 2016;128(4): e147-54. 